\title{
On EST Translation Skills
}

\author{
Li Jin-ping \\ (Hunan Railway Professional \& Technology College, Zhuzhou, Hunan China 412001) \\ Shirley5152@sina.com
}

Key words: Translation skills, EST; Translation ability

\begin{abstract}
This article analyses on the translation skills of EST (English for Science and Technology) from the title, vocabulary, nominalization, passive voice as well as language fragments phenomenon. It mainly aims to improve the students' translation skills of EST.
\end{abstract}

\section{Introduction}

After many investigation and research, we found that the measures we used in public English teaching lead to some difficulties that graduates have to devote a great deal of time and energy to adapting what their jobs required in the later work. Therefore, we should take the occupation characteristics and specific job requirement into consideration and English curriculum reform could meet various competency requirements in order to develop students' ability of using English. Nevertheless, EST has its own features, so people should be agile and use different translation methods and techniques in translating EST.

\section{Characteristics of English for science and technology}

English for science and technology is accurate, objective, formal, rigorous logic; it's content sentence structure are the concise, focused, rigorous and have rare change ${ }^{[1]}$. Translation of English for science and technology emphasize on the primary information conversion between two languages. Hence, translating EST focus on being faithful to the original, understanding the English original and conveying accurately the original content containing the characteristics of scientific and technical information characteristic, making the content is understood easily. Moreover, Extensive use of nominalization and extensive use of the passive voice are two remarkable characteristics of English for science and technology.

\section{Techniques of EST translation}

\section{1) The title translation of English for science and technology}

English title should not only complete and accurate expression Chinese the meaning of the title, but also should accord with the habit of expression in English instead of simply list the words and translate word for word. Therefore, tips of translating titles of scientific papers can be divided into three dimensions: pre-modifier + the word, word + postpositive attributive. When we translate scientific paper title, except being faithful to the original, being concise and highlighting the core principles, we should also pay attention to seize the key words: Chinese Title phrase are used to partial structure which place first modified terms in front and put the key words behind. Understanding these characteristics of English translation, we need to find the key words first and then place them in a prominent position, after that, adding modifier in front of these key words.

E.g: (Original): "Mei steel production management under ERP environment”

Translation: "Production Management under the Circumstance of ERP".

Here the key word of the title is "production management", so we should seize the word, translate it and placed in the front, plus modifier. 
Some papers use the question as a title, because the whole paper need to answer and discuss the questions that contended, in that condition, translating the title should emphasize on the interrogative in question title including complete question, omit the question and interrogative which take the infinitive phrase.

E.g: "how to write a scientific paper" can be translated into: "How to write a paper for scientific and technological treatise"

\section{2) Translating words of EST}

Understanding word meaning correctly and choosing the proper word are the foundation of translating English words for science and technology. Because some words meaning varied from English to English for science and technology, we need should pay attention to determine the meaning according to its professional content with comprehensive insight.

E.g: Press the power button on the monitor.

Here “monitor" generally mean "monitor", nevertheless, it can be translated as: “display screen" in the computer professional content ${ }^{[2]}$.

In the process of translation, we often encounter with some words that can not be translated by using proper words from English dictionary, if arbitrarily mechanically or word for word translation will cause death, curt obscure translation, not the exact expression of intent, and even cause misunderstanding. So what we should do is to understand specific logical relations and basic meaning of the word, and then extend its meaning with the subject according to the related context.

E.g: the original: If no press is available, the clutch parts may be heated by a torch through the bore.

Translation: If no press is available, the clutch parts may be heated by a torch through the bore.

Here the word "press" (strengthen pressure) esp. means using something to strengthen pressure on bearing ring-side "[3].

\section{3) Translating English nominalization structure in EST}

Because of the differences between English and Chinese expressions, some abstract nouns of English for science and technology should be translated into Chinese verbs or other parts of speech. Some nouns which mean actions are actually concentrated sentences. These kinds of nouns should be translated into Chinese sentences with adding subjects. This can avoid rigid, cumbersome and awkward translation from copy the original structure.

There are many nominalization structures in EST. Such as: nouns (nouns of action) + preposition + noun; Verb and verb noun collocations, structure or "Verb + noun structure; noun + noun (verbal noun). ${ }^{[4]}$

When translating nominalization structures, some skills as followed can be used: Analyzing the structure from its literal to the implicit meaning; from its lexical concept to relative meaning; in perspective not rigid \& isolated view to understand. If we apply these skills in translating, the translation would conform to the rules and requirements of Chinese.

E.g: They were aided by the establishment of societies that lobbied for governmental agencies of agriculture; the voluntary cooperation of farmers through associations; and the increasing use of various types of power machinery on the farm.

Conversion 1: Spontaneous cooperation between farmers called on the government to set up agricultural institutions of community through associations and use large-scale power of machinery on the farm, which offered them a lot of help.”

Conversion 2: They establish associations to lobby government department of agriculture; spontaneous cooperation through association; more use of power machinery on the farm, all this 
makes them benefit ${ }^{[4]}$ 。

In conversion 1, the students remain three noun structure of the original but didn't make necessary change. So the conversion reads very awkward. While in conversion 2 , some changes and modifications have been made and the conversion reads smooth, natural and conforms to Chinese expression custom.

Well-structured and with a large amount of information are the features of EST articles. That's why the nominalization structure is widely used. Verbs are used much more in Chinese than in English. Therefore, those nouns with meaning of action or gerunds should be translated into Chinese verbs so as to conform to Chinese expression custom.

\section{4) Translating passive voice in SET}

The frequent use of the passive voice is one of the highlighted features of EST. According to the statistics of University of Leeds John Swales, about 1/3 of the predicates in EST are passive voice. This is because the scientific articles focus on narrative reasoning, emphasizing the objective and accurate. A subjective view or assumption will be produced when the first or the second person is used too much. So we try to use as many passive voices as possible and in the third person.

In contrast, passive voice is used much less in Chinese than in English. And many passive sentences in English can be translated into active passive sentences in Chinese, or into active form with passive meaning, or into complete active sentence converting its predicates of the original, or from passive voice directly into complete active sentence.

e.g. Chemical fertilizers were manufactured in greatly in creased quantities and soil analysis was widely employed to determine the elements needed by a particular soil to maintain or restore its fertility.

Chinese translation: "Because of the increase of fertilizer production, people have to analyze soil in order to maintain or restore soil fertility components." [5] rules, this sentence is translated into Chinese active sentence with no subject.

No subject is a special sentence pattern in Chinese. Many sentences in English which don't need or can't tell one their behaviors can be translated into subject- less Chinese sentences, converting the original subjects into Chinese objects.

e.g. Pills should be taken three times a day (Chinese translation: one should take pills three times a day.) The original English subject still do the subject in translation in Chinese by using some words which has passive meaning in the text. Besides, personal pronouns (such as: people, all, etc.) always are added as the subjects in translation in Chinese.

e.g: It is thought that this plan won't act. (Chinese translation: all thought that this plan won' act. In this translation, the subject "it" is omitted while adding "all”(people) as the subjects in Chinese.

In addition, isolated parts or components in some long and difficult sentences in EST are important factors or reasons to cause misunderstanding and misinterpretation for students. These isolated parts or components are special forms of expression and also are features of long and difficult sentences in EST. These parts or components can be rigorous, scientific and can avoid misunderstandings.

. The following expressions are often fragmentation and isolated parts or components, prepositional phrases, participle, the infinitive phrase; clauses; additional component of the sentence, such as inserting component, apposition and independent components etc.

e.g: In North America, agriculture had progressed further before the coming of the Europeans than is commonly supposed.

Wrong translation: In people's imagination, American agriculture had progressed further than 


\section{in European.}

Right translation: Before the coming of the Europeans, the American agriculture had far progressed.

Prepositional phrases" before the coming of the Europeans” in the text is an adverbial of time, meaning "it is the adverbial of time that departs the two comparing components far in this sentence and misunderstanding and misinterpretation appeared

\section{Conclusion}

Scientific article is hard to translate. Except some unfamiliar and special vocabulary, there are some grammatical phenomena in EST are hard to explain and understand, such as Noun sentence structures, the passive sentences, etc. all these often cause misunderstanding and mistranslation in the process of understanding and expressing. In order to improve our translating ability, we haven't only to enlarge our vocabulary, look up the dictionary but also master some skills of translation, understanding and expression.

Translation is not only a theory to teach students the basic law but also a practical course to guide students in translation practice. Only under the guidance of the theory and engaged in plenty of translation practice, practical translation ability of students can be improved.

\section{Reference (Bibliography):}

[1] Zhao Qizhi. On Translation skills of technical English, Shanxi Science, Vol.6(2006 ), p.62-63

[2] Wu Yan. On titles translation in technology \& science papers, Meishan Science, Vol.1(2006 ), p.60-61

[3] Lu Xiaozhen. Translation of words in English technological \& science articles, English for science and technology, Vol.6(2005), p.35-36

[4] Sun Libing. Attention to some problems about the translation of scientific and technological articles-- thinking after a translation practice for students, Mass Data, Vol.12(2006), p.157-158

[5] Wang Huan. Study on characteristics and translation of English science and technology, Social Science, Vol. 22(2006), p.187-188 